University of Warwick institutional repository: http://go.warwick.ac.uk/wrap This paper is made available online in accordance with publisher policies. Please scroll down to view the document itself. Please refer to the repository record for this item and our policy information available from the repository home page for further information.

To see the final version of this paper please visit the publisher's website. Access to the published version may require a subscription.

Author(s): Oswald, Andrew

Article Title: Economics that Matters: Using the Tax System to Solve the Shortage of Human Organs

Year of publication: 2001

Link to published version: http://dx.doi.org/ 10.1111/1467-6435.00159

Publisher statement: The definitive version is available at www.blackwell-synergy.com 


\title{
Economics that Matters: Using the Tax System to Solve the Shortage of Human Organs
}

\author{
by
}

Andrew Oswald, Professor of Economics, University of Warwick

Although most people are unaware of it, the world faces a critical shortage. There are too few organ donors. Every hour, one American and one European die for want of a transplant donor. Yet in principle there are enough natural (though tragically untimely) deaths to provide sufficient donors for our citizens.

New ideas are therefore essential: we have to find a way to match supply with demand. While this is a complicated and sensitive area of human life, it would be sensible for our nations to offer a small tax incentive to those willing to carry a donation card and act as potential organ donor in the event of their own death. This is an economic approach. But it could solve a medical problem.

There is clear need. In the United Kingdom, for instance, approximately 6000 people are waiting at any one time for transplants of major organs - especially kidney, pancreas, heart, lung, liver. Underlying demand is even larger than this suggests. If the supply of organs were greater, the official waiting-list figure would be longer. Around 3000 transplants are done each year in the UK.

In the United States, at any time 70,000 men and women are waiting for a transplant of a major body organ. The annual number of transplants in the US is only approximately 20,000 . Clearly there is something fundamentally wrong with the matching of supply and demand.

The National Kidney Foundation of the USA estimates that 50 Americans die each week for want of a kidney donor alone. 
Throughout the world, the great bulk of all organ transplants are from cadaver donors (that is, after the death of the person donating the organ). In addition to these statistics, large numbers of eye cornea transplants are done. These are successful and comparatively inexpensive.

A tax scheme could run like this. It would offer a small lump sum reduction on a person's income tax bill if he or she agreed to be a potential donor in the future. It is unlikely that the size of the incentive would have to be large. A tax break would itself serve, by offering a box to tick on a tax form, to highlight a problem about which few now speak; it would be effective advertising; and human altruism the a small incentive would do the rest. Subsidizing altruism, although policy economists have not thought a lot about, seems to make sense.

Say the tax reduction for a person were 10 pounds (15 dollars) a year. In a country such as the United Kingdom, there are around 20 million taxpayers of working age. This might mean a cost to the Exchequer of 200 million pounds sterling. Arguably, the tax incentive and publicity would more than double the stock of officially registered potential organ donors from its current 8 million people. If so, it might be feasible to increase the number of transplants by around 2000 a year. The implicit tax cost in a nation like the UK would then be close to 100,000 pounds per annum per extra transplant.

Although this is a large sum, it is not unacceptably great. There are enormous costs of providing, for example, kidney dialysis treatment to those waiting for a transplant. The lost income from having workers incapacitated is considerable. More important, the value in pain and suffering from major illness might be considered to make efficient any tax scheme that could deliver such an outcome.

Of course similar set-ups could work in other nations. The shortage of human organs is true in all of the advanced industrial economies.

Moreover, this problem is not going to go away in our lifetimes, for the following reasons.

Paradoxically, economic progress is worsening our difficulties. First, the wearing of seatbelts and improved safety design of vehicles has 
decreased the number of organ donors. Second, medical advance has raised the usefulness of donations. Preservation techniques and immune-system suppressants have improved. A kidney now is able to be used up to 72 hours after the death of the donor; a pancreas up to 20 hours; a liver 18 hours; and a heart up to 5 hours afterwards. In the United States, $90 \%$ of kidney transplant patients are alive and well at one year from the operation. Even for heart transplant operations, the US figure is $85 \%$ after one year. Third, people everywhere are living longer. This sheer fact of increased longevity will make it vital to solve the demand-supply imbalance in organs.

It is against the law, in our nations, to trade in human organs (for good reason). It would be too hard to regulate across very rich and very poor countries. Contracts could not be enforced. There would be incentive for extremely unpleasant kinds of crime. And, realistically, public reaction would be harshly against economists proposing a marketplace in human organs.

Moreover, voluntary sign-up donation mechanisms are not as successful as required - probably because people prefer not to think about death. Hence there is a missing market, an economist would say. So governments must step in.

Ensuring a supply of organs, though it sounds terribly hard-hearted to put it in that language, really matters, and will become increasingly important in western society. The provision of small tax incentives for altruism seems a natural way to go about this.

Would some view tax breaks for potential organ donation as morally objectionable? Perhaps.

However, virtually all religious denominations officially support the principle of organ donation. The alternatives, too, are unattractive. Most countries' citizens will never allow the buying and selling of organs (though Harris 2000 hopes that one day they will). As life-spans stretch towards 100, the underlying problem is not going to go away. The alternative of so-called 'presumed consent' or, in other words, compulsory opt-in is unappealing. This is the idea that all citizens should be assumed, unless they have signed a waiver, to have agreed to allow their organs to be used in the event of, for example, their death 
in a car crash. Yet automatic opt-in seems unreasonable. The current kind of approach - where people do not donate unless they have specifically consented - is surely a more natural one in a democracy.

We need to act. Tax incentives for organ donation would be the right path to take. In this sphere of life, things simply cannot be left to market forces. And life, here, means just that.

\section{$\underline{\text { References }}$}

Harris, John. 'Transplantation and the Duty to Others'. Working Paper, Manchester University, The Institute of Medicine, Law and Bioethics. February 2000. 